\title{
Study on Building Service-Oriented Environment Management Model Under the Synergistic Demand of Environment Protection and Industrial Upgrading
}

\author{
Shi Bi-tao \\ School of Economics and Management, Dongguan University of Technology, Dongguan, China
}

Email address:

sbt99@sohu.com

\section{To cite this article:}

Shi Bi-tao. Study on Building Service-Oriented Environment Management Model Under the Synergistic Demand of Environment Protection and Industrial Upgrading. Science Discovery. Vol. 5, No. 6, 2017, pp. 444-449. doi: 10.11648/j.sd.20170506.19

Received: September 24, 2017; Accepted: October 5, 2017; Published: November 21, 2017

\begin{abstract}
At first theoretically analyzes dialectical relation among management model transformation, improving environment protection effect and boosting industrial upgrading, then discusses the significance of building service-oriented environment management model from nationality, necessity and feasibility, points out that service-oriented environment management modelshould be built under the principle of strict environment governance, win-win result between environment and development can be got only if the balance between governance and service is kept and environment management model is scientifically innovated. At last, according to China's reality, some strategies are given on building China's service-oriented environment management model from ideology, superstructure, hardware improving, software perfection and treatment of special circumstances.
\end{abstract}

Keywords: Service-Oriented Government, Environment Management, Environment Protection, Industrial Upgrading, Synergistic Development

\section{环境保护与产业升级协同诉求下我国的服务型环境管理模式建设}

\author{
石碧涛 \\ 经济与管理学院, 东莞理工学院, 东莞, 中国 \\ 邮箱 \\ sbt99@sohu.com
}

摘要: 首先从理论层面, 分析了转变管理模式、提升环保成效、助推产业升级三者之间的辩证关系, 其次从合理性、 必要性、可行性等方面论证了服务型环境管理模式的建设意义，指出服务型环境管理模式的建设必须以严格环境管制 为基本原则, 对“管治”与“服务”职能进行优化平衡, 科学合理地进行环境管理模式的创新, 才能实现环境与发展的双 赢。最后, 针对中国实际状况, 从意识形态、上层建设、硬件提升、软件完善与特殊情况处理等五个方面, 给出了中 国建设服务型环境管理模式的具体对策。

关键词：服务型政府，环境管理，环境保护，产业升级，协同发展 


\section{1. 引言}

中共十八大政府工作报告提出要把生态文明建设列 到与经济建设、政治建设、文化建设、社会建设同等的高 度, “五位一体”地建设中国特色社会主义。环境保护工作 被摆在更加突出重要的位置。十八届三中全会之后, 政府 职能转变被提上更为重要的日程。转变政府职能, 提升环 保工作的成效, 切实改善环境质量, 成为当前环境管理改 革的重要内容。目前, 管理学者已经对服务型政府的理论 基础、实施途径进行了充分的论证，提出了众多切实可行 的对策和建议，但服务型政府管理模式的建设仍然是一个 漫长的过程, 需要不断地探索与实践。

对于环境管理而言, 由于环境质量存在明确的限值标 准, 环境监管的基本职能不能弱化。在严格环境监管的前 提下, 强化环境管理中的服务型特色, 从而更好地为环境 保护和社会经济发展服务, 成为中国环境管理工作改革的 突破点。当前中国经济建设工作的重点是推进产业转型升 级, 实现经济良性健康发展。随着社会经济的不断发展, 人们越来越多地关注环境保护与经济发展之间的关系, 而 对环境保护与产业升级之间相互影响的路径及原理却重 视不够。如何在妥善保护环境的同时, 推动地区产业升级 的快速发展, 成为当前中国重点关注的内容和迫切需要解 决的问题。

所以, 本文针对环境保护与产业升级协同诉求下的服 务型管理模式进行探讨, 期望通过厘清环境保护、产业升 级、政府管理三者之间的辩证关系，探讨环境管理模式中 的“管治”与“服务”职能的平衡, 提出服务型环境管理模式 建设的对策, 为深化中国环境管理工作改革, 实现环境质 量改善与产业转型升级的协同发展提供科学依据。

\section{2. 研究背景与研究思路}

\section{1. 研究背景}

\subsection{1. 服务型政府}

十八届三中全会指出必须切实转变政府职能, 深化行政 体制改革, 创新行政管理方式, 增强政府公信力和执行力, 建设法治政府和服务型政府 [1]。根据西方“新公共管理”思想， 服务型政府的内涵是强化公共服务职能、满足民众需求、回 应民众诉求迅速的政府[2]。简言之, 服务型政府的核心是有 限政府、法治政府、责任政府、透明政府[3]。

吴玉宗（2004）等提出了建设服务型政府，构建公共 服务型政府创新体系的具体内容 $[4,5]$ 。胡伟和柳美玲 （2014）等从实践角度对中国三十余座主要城市的服务型 政府建设情况进行追踪性调查研究, 并相继推出“连氏中 国城市公共服务质量指数”和“连氏中国城市服务型政府 指数” $[6,7]$ 。

\subsection{2. 我国的产业升级}

以劳动密集型和资源消耗为特征的发展模式已不可 为继, 函需实现产业转型升级 [8]。李萍和谌新民（2012） 提出产业升级需要实施自主创新战略, 培育高新科技, 提
高区域品牌能力建设, 实现产业系统化, 发展内源经济与 循环经济, 提高节能和减排技术进步[9]; 何云 (2002) 则 从生态角度提出建设经济与生态资产的增长与积累的共 同富裕, 人的身心及生态系统服务功能与代谢过程的共同 健康, 物质、精神和生态文明的共同文明, 实现三位一体 的复合生态繁荣 $[10]$ 。

\subsection{3. 环保形势}

近年来公布的中国环境状况公报指出, 尽管我国在环 保领域开展了大量工作, 加大环境保护力度, 但全国环境 质量总体仍然一般[11]。环境污染的范围和广度已经超过 历史任何时期。中国发展的多项趋势表明, 如果不采取适 当的政策干预, 中国的城市环境将进一步恶化。

为了应对环境问题, 中国目前建立了法律、行政法规、 部门规章、地方性法规和规章、环境标准、环境保护国际 条约组成的完整的环境保护法律法规体系。在此基础上, 建立了包括新老八项制度在内的环境管理体系框架, 还有 各种环境标准、总量控制、地方性规定等[12]。但是, 多 次上演的市民悬赏让环保局长下河游泳的闹剧, 从侧面反 映出市民对当前环境管理模式的不满。

\section{2. 研究思路}

本文旨在研究环境保护与产业升级协同诉求下的服 务型环境管理模式建设, 其核心意义是: 建设一种服务型 的环境管理模式, 实现对环境质量改善与产业转型升级的 有效推动, 并且实现环境质量改善与产业转型升级之间的 相互促进, 进而实现地方环境与经济的协同发展。图1简 单示意了三者相互作用的模型。

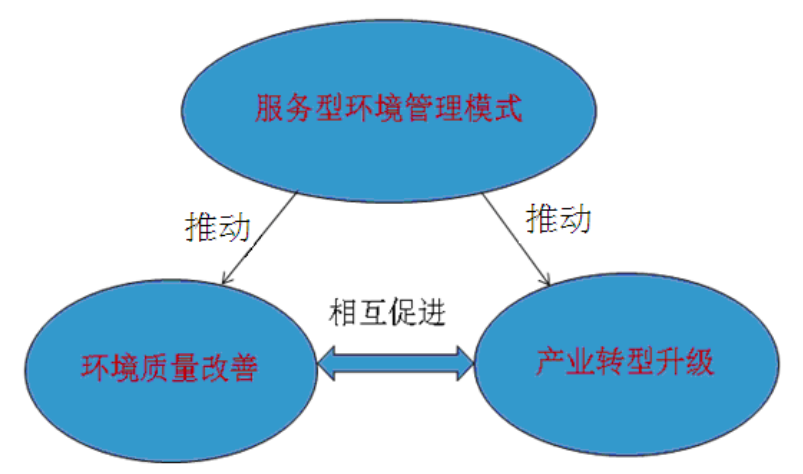

图1 环境管理、环境保护、产业升级的相互作用概念模型。

为了阐明该概念模型, 需要解释以下几个问题:

（1）中国越来越多地关注服务型政府的建设, 但对 环境管理而言, 由于环境标准的执行具有不可动摇性, 在 服务型政府管理模式中, 环境管理的服务性如何体现, 即 如何处理好“监管”与“服务”之间的平衡。

（2）环境保护是基本国策。近来中国的环境问题备 受关注, 特别是以长三角、珠三角和京津冀为代表的工业 快速发展区域, 要实现环境质量的有效改善, 严格的环境 监管不可废。因此, 适当改变环境管理模式, 是否更利于 保护环境? 
（3）发展是第一要务。当前, 中国各级政府首要关 心的主题仍然是发展, 尤其关注产业转型升级。而另一方 面, 环境保护成为经济发展羁绊的观念, 在很长时期、在 许多地方仍然存在。在有效推进生态文明建设的同时, 环 境管理体制改革如何更好地服务于社会经济发展?

（4）当前有一种认识, 认为产业升级必然有利于环 境质量改善, 即产业升级后的污染物排放更少, 环境危害 更轻。其实, 这是一种片面的观点。产业升级更强调自主 创新与品牌战略对产品附加值的提升, 而不能简单等同于 绿色工业、循环经济, 由于存在负外部性, 有些高科技、 高附加值产品的环境污染威胁更大。产业升级并不意味着 环境改善。如何在促进产业升级与经济发展的同时，确保 环境质量改善?

纯原生态的环境, 其质量肯定会好一些, 但毕竟社会 经济要不断发展。研究面临发展为主题的城市如何实现环 境质量改善与产业转型升级之间的协同发展, 无疑具有很 强的现实意义。所以, 本文将从以下三个方面对环境保护 与产业升级协同诉求下的服务型环境管理模式建设进行 研究:

（1）分析环境保护与产业升级协同诉求下的服务型 环境管理模式的需求, 针对当前社会环境管理模式、环境
质量改善、产业转型升级三者之间的相互影响与制约因素, 阐明为什么要建设协同诉求下的服务型环境管理模式。

（2）探讨在环境保护与产业升级协同诉求下建设服 务型环境管理模式的可行性。从服务型环境管理模式对环 境质量改善和产业转型升级的有效推动, 以及环境质量改 善与产业转型升级之间相互促进的角度进行分析, 为中国 建设服务型环境管理模式提供理论支撑。

（3）在回应环境保护与产业升级的协同诉求下, 中 国建设服务型环境管理模式的对策建议。根据环境质量现 状、环境管理方式、产业发展现状与产业升级需求, 结合 经济发展实际, 提出具体政策建议, 推动服务型环境管理 模式的建设。

\section{3. 协同诉求下环境管理模式转变的需求分析}

\section{1. 环境污染与产业升级}

研究经济与环境的关系, 经典的理论应该是“环境库 茨涅兹曲线”（EKC）。Grossman和Krueger（1995）在实 证分析的基础上提出了“环境库茨涅兹曲线” (EKC) (见 图2）。该曲线描述的是发达国家整体环境质量随着经济 增长的推进呈先恶化后改善的趋势, 认为环境质量同经济 增长之间呈倒U型曲线关系[13]。

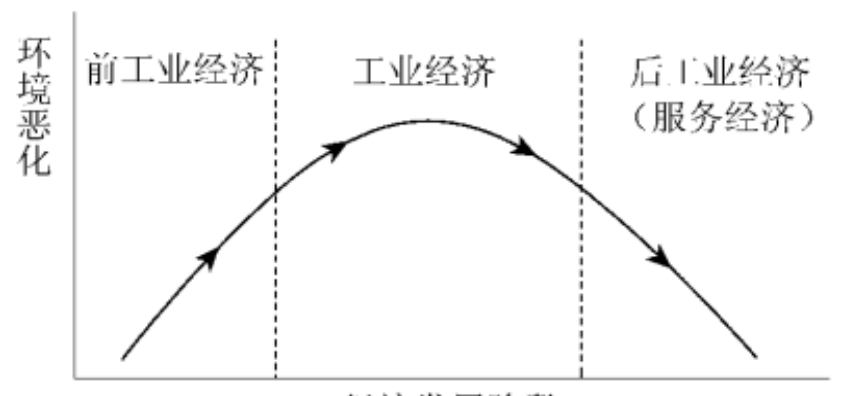

经济发赴阶段

图2 环境库茨涅兹曲线。

中国国内研究者对环境库茨涅兹曲线的中国应用进 行了相关研究, 指出虽然存在一定的差异性, 但相似性较 大，即中国与发达国家一样将经历“先污染后治理”的道路 [14]。按照该理论, 中国可能逐渐接近于库茨涅兹环境曲 线的转折点。造成环境污染的主要原因是中国的工业发展 水平低下, 在绝大多数产业领域, 中国的产业结构处于全 球价值链分工体系中的低端环节, 无论是传统轻工业, 还 是重工业都依赖于资源消耗大、技术含量低的劳动密集型 产业, 从而导致投入大量资源生产的产品附加值低, 消耗 的能源等均较大, 最终导致严重的环境污染。

为了应对残酷的国际竞争形势、从根本上改变环境污 染现状, 中国提出了产业转型升级的战略。一方面, 通过 产业升级, 发展低碳环保工艺, 生产绿色产品, 降低污染 物的排放。前文提到, 这里可能存在一个误区, 即认为技 术含量高的高科技产品污染较低。其实这两者并没有直接 的关系，很多高科技产品反而伴随着更多或更难以处理的 污染物的排放。所以单纯依靠产业升级来应对环境污染问 题还不够, 需要多措并举, 加强政府服务管制。另一方面,
产业转型对环境保护有较好的促进作用, 比如中国国家产 业政策明确规定的需要淘汰的低端产品与生产工艺, 对其 限制无疑有利于保护环境。某些地方为了加强环境保护, 强制淘汰部分产业或转移某些工厂, 明显提升了环保成效。 但对整个国家而言, 产业转移并不是根本解决之道, 一个 污染严重的工厂换个地方仍然会造成污染。所以, 要实现 环境保护与产业升级的协同发展, 需要从意识形态、管理 规范、具体措施等多方面着手, 形成系统, 构建体系, 方 可见成效。

\section{2. 环境管理体制与环境质量改善}

自2008年环保部成立以来, 中国环境保护体系建设开 始进入快速发展阶段。目前已经形成了由环境保护法律、 法规、政策和行政执法等构成的相对完善的环境管理体系, 对污染排放、资源消耗等问题进行了初步卓有成效的控制。 但当前中国环境管理的成效与国民的期待仍有较大的差 距, 中国仍然需要对当前的环境管理模式进行深入改革。 
首先需要说明, 环境管制对保护环境而言, 是不可动 摇的基本原则 [15], 所以严格的管制是环境保护工作的前 提。但在严格管制基础之上, 对环境管理模式进行优化并 促使其不断进步是可以做到的。尤其是在中国, 政府管理 模式本身就具有创新性与不成熟性, 政府管理工作也需要 不断完善。顺应时代发展的形势和国家发展需求, 采取更 有效、更合理的环境管理模式是有基础的、可行的，服务 型环境管理模式就是其中之一。

根据服务型政府管理模式的内涵与外延, 服务型环境 管理模式可以在公共环境服务、民众环境诉求回应、环境 信息共享、环保平台建设等方面，对管理的目标、方法、 方式等进行优化, 从而更好地提升环保效率。

\section{3. 环境管理与产业升级}

在中国, 产业升级一般是由政府提出并由其主导。相 对而言, 产业个体的主动性升级动机较弱。在利益驱动下, 企业主更关心利润的最大化, 经常被动地去思考产业升级, 尤其是忽略环境保护层面的产业升级。基于节约成本等考 虑, 企业可能采用对环境不利的新技术、新工艺, 结果反 而破坏了环境, 因此不能单纯依靠市场机制, 需要加强政 府规制。

环境管理是政府管理的一部分, 基于环境质量破坏的 不可接受性, 政府通常以严厉执法的形象来介入产业升级 过程。对于一种产业行为, 无论是在立项、建成投产还是 在日常环境管理阶段, 政府都可以施加重要影响。在这些 产业行为中, 政府职能更多体现在环境管制方面, 尤其是 偏重事后监管, 纠正和惩罚错误。

关于环境管制对产业升级的影响, 经典的经济学解释 应属“波特假说” [16]。该假说强调“适当的环境管制”，不 适当的环境管制则会影响产业发展与转型升级。而中国城 市的环境管理, 虽然可排除对产业升级造成负面影响的可 能, 但在强调其促进作用方面仍然存在诸多不足。所以, 在严格环境管理底线不放松的前提下, 通过转变环境管理 模式, 提高环境保护的质量, 促进地区产业升级, 对中国 而言意义重大。

\section{4. 协同诉求下服务型环境管理模式建设的可行 性分析}

\section{1. 服务型环境管理模式对环境质量改善的促进作用}

服务型政府的核心是有限政府、法治政府、责任政府 与透明政府。其管理和服务对象既包括工业企业，也包括 社会民众。相应地, 服务型环境管理必须是服务完善的环 境管理，依法合规、遵守标准的环境管理，对人民负责的 环境管理, 以及公开透明的环境管理。针对中国当前的环 保现状, 服务型政府架构下的环境管理模式显然会极大地 推进环保工作。

首先, 依法合规遵守标准的环境管理, 会较大地促进 环境保护工作。环境要素的质量不可降低性决定了环境监 管的职责不仅不可废, 而且需要进一步加强。依据相关的 法律法规, 保证区域性环境要素符合质量标准, 是更好实
施环境保护工作的根本。有法不依, 执法不严, 规范与标 准不能得到严格执行，不可能保证环境质量得到改善。

其次, 对人民负责的环境管理, 会更及时有效地推动 环保工作实施。市民对自己生存的环境提出要求, 政府实 施环境管理对市民负责, 负责任才有作为, 才能有效保护 环境。服务型环境管理强调以民为本、以客为尊的服务理 念, 可以保证环境保护工作及时有效地实施。

再次, 公开透明的环境管理, 会保证环境保护工作高 效推进。过去相当长的时间内, 由于信息不公开、不透明, 导致市民对环境状况的感受决定了其对环境质量的认识。 服务型环境管理模式则强调信息公开透明, 公众可以第一 时间了解环境状况与环保措施的成效, 企业可以学习有效 的环保知识与技术, 可以更好地推动环境质量的改善。

最后, 服务完善的环境管理, 可以提升环境保护工作 的技术水平与服务质量。服务型环境管理模式要求确立明 确的环境服务标准，理顺职能分工，制定规范化的服务细 则与办事流程导引图、职位职责说明书，建立公开便捷的 民众申诉渠道, 借以提升环境保护工作的时效, 有效改善 地区环境质量。

但必须注意到, 政府管制也有局限, 存在信息不对称、 成本高等, 因此政府的服务型管理还要借助社会的第三方 治理, 即民众和社团组织的广泛参与, 以提高环境透明度 和监管效率。

\section{2. 服务型环境管理模式对产业转型升级的推动作用}

服务型环境管理模式对产业转型升级的推动作用, 可 以结合产业升级的诉求和服务型环境管理模式的架构进 行分析。产业升级的诉求是实施自主创新与品牌战略, 提 高产品的附加值, 服务型环境管理模式强调环境管理的服 务完善、依法合规遵守标准、对人民负责与公开透明。架 构合理的服务型环境管理模式, 可以通过事前、事中和事 后的服务、监管及执法极大地推动产业升级的进程。

对于产业升级而言, 服务型环境管理模式可以为企业 带来直接的好处。首先, 服务型环境管理可以为现有企业 提供完善的环保服务, 帮助企业在提高技术水平与产品附 加值的同时, 以经济、高效的环保技术解决所存在的问题, 而不是生硬的强制转产、转移、转型。对招商引资新产业, 服务型环境管理模式通过提早介入、事前辅导, 在项目规 划阶段为其提供完善的环保服务。

完善的环保服务其实可给企业带来几方面的直接好 处:

(1)为企业增值。环保服务可以帮助企业应对诸如国际 碳关税、“ROHS”指令等环保限制性法则，提高“中国制造” 产品在国际市场上的价值。环保服务可以协助企业提升品 牌效应, 一个对环保负责的企业通常都会获得市场更好的 认可。

(2)为企业省钱。目前环保管理体制下, 企业通常在“信 息不对称、不公开、不透明”的情况下, 浪费了大量的钱 财。比如一些企业在面对改扩产时的审批, 可能采取一些 不必要的行动, 要花冤枉钱, 而服务型管理模式可以及时 让企业清楚应该怎么做。 
(3)促进企业改进管理水平, 提高清洁生产水平, 从而 节能、降耗、减污、增效。因为环保工作涉及生产活动的 全过程, 包括审批、建设、试运行、运行、清洁生产、节 能降耗、环境应急等众多环节, 服务型环境管理模式可以 帮助企业提高管理水平，改进生产工艺，完善生产技术。

(4)推动中国环保产业的发展。发展优秀的环保产业, 可以创造新的经济增长点, 促进地方经济的发展。尽管潜 力巨大, 但是中国环保产业尚未迈入快速发展阶段, 总体 规模和产值相对还很小。服务型环境管理可以提升环保产 业的技术水平、系统服务水平、品牌价值, 从而使环保产 业对经济的直接贡献由小变大, 逐渐成为改善经济运行质 量、促进经济增长、提高经济技术档次的产业。

\section{3. 环境质量改善与产业转型升级之间的相互促进}

环境质量改善与产业转型升级之间的相互促进包含 两层含义: 一是环境质量改善对产业转型升级而言可以起 到有效的促进作用, 二是有序的产业升级会促进地区环境 质量的改善。

当前的主流观点认为, 产业升级是作为地方解决区域 环境问题的一种手段, 产业升级发展得好, 环境质量必然 会随之得到改善。产业升级既包含规模与绩效内容, 又包 括能源与环境的特征, 还包括产品附加值提高的含义。对 企业和国家而言, 都具有重要的意义。企业意识到市场上 存在着对绿色产品的需求时, 潜在的收益指日可待, 因而 提供绿色产品也就是经济自利性驱动的必然结果。改进环 境质量通常是企业提高效率、进而提高利润率的最佳途径。 对国家而言, 淘汰了低附加值高污染类传统落后产业, 大 力发展工业园区, 提高现代战略新兴产业的自主创新与品 牌战略, 已经较大地提升了地区的环境质量[17]。

环境质量的改善对企业产业升级的促进作用更多体 现为长期效应与深层次效应。那些采用环境保护技术的企 业相对于仍采用传统落后技术的企业来说, 还可以获得包 括创新、效率、整合等在内的一系列竞争优势 [18]。环境 与经济最终将趋于和谐, 企业与环境都会成为赢家; 绿化 不再构成经济运行的成本。相反, 它将成为持续创新、新 的商机以及财富创造的催化剂。一个生态宜居的城市会从 整体上提升企业的品牌价值，提高城市营销与企业营销的 成效; 环境质量较好的城市也会有更多的资金支持企业技 术研发与自主创新; 生态宜居的城市也会明显提升企业对 人才的吸引力, 使更多乐意在城市安居乐业的人才更投入 地工作; 甚至生态宜居的城市对企业本身固定资产的价值 都有提升作用等等。所以, 地区的环境质量改善对产业升 级的影响是深远的。

\section{5. 中国建设服务型环境管理模式的对策建议}

总的来说, 服务型环境管理的治理原则应该是监管和 服务前移, 防患于未然, 犹如中医的“治未病”, 而非简单 的事后执法如山, “不教而诛”。这也是处理好服务型管理 与严格监管两者关系的关键, 即通过周到的服务, 尽量让 企业不要犯错, 但一旦犯错则是“零容忍”。具体对策如下：
5. 1. 在意识形态方面, 通过教育、宣传等途径, 倡导服 务型环境管理的理念

建设服务型环境管理模式首先要树立“民本位”思想, 强化以民为本、以质为尊的服务理念。要提高环保行政管 理部门的服务意识和服务水平, 培养其服务型管理理念, 为企业服务、为环境改善服务、为产业升级服务。对于涉 及环保领域的企事业单位工作人员, 要进行宣传、引导、 教育, 使其明确服务型环境管理的理念、做法与途径, 真 正做到为地区的环境改善共同努力。对普通民众, 通过“环 境日”活动以及日常的环保宣传、教育行为, 理解环境管 理的服务性, 参与环境保护行动, 建言献策, 共同努力, 亲身参与到生态文明建设工作中去, 最终实现碧水蓝天、 生态和谐。

\section{2. 在上层建筑方面, 出台相应的法律法规、政策标准, 为服务型环境管理模式建设提供制度规范保障}

服务型管理模式是依法合规尊重标准的管理模式, 国 家、省层面制订完善相应的规范, 各地需要根据本地区实 际, 在严格的环境监管的基础之上, 制定符合环保需求和 产业发展诉求的施政目标, 出台相应的制度、规范、标准, 使服务型环境管理模式的建设得到保证并且有章可循。第 一, 按照创新行政管理体制的要求, 确立明确的环境管理 服务标准, 不断提升环境管理部门的服务功能。第二, 在 政府能力所及范围内, 科学、经济和有效率地提供环境管 理服务, 并根据标准进行绩效评估。第三, 强化环保执法 部门的执法权威, 保障环保法律得到有效实施。第四, 建 立公开且便捷的民众申诉渠道, 相应地要建立独立的审查 制度。

5. 3. 在硬件提升方面, 完善相关平台、网站、渠道, 加 大服务型环境管理模式的建设力度

完善在线环境监测网络系统, 增设环境监测分站、点, 形成“10+1”大气复合污染立体监测以及水源监测网络。完 成环境综合管理信息系统建设, 推进网上办事大厅建设工 作, 全面启动环保数字管理平台建设; 建立企业环境保护 工作情况共享平台, 通过企业环保案例展示和成功的环保 技术共享, 推动企业环境保护工作。

\section{4. 在软件完善方面, 构建服务型环境管理体系, 着力 落实服务型环境管理模式的建设}

设立地方环境保护委员会和常设办公室, 推动环境应 急体系建设, 整顿环保行业部门的作风、规范行政行为, 提升政府形象。借助环境科学学会、环保产业协会等社会 团体，强化对环境保护和产业升级的技术服务与政策宣导。 继续简政放权、推进机构改革、完善制度机制、提高环保 行政效能。建立和完善环境管理议事、决策的规则和程序, 依据法律、法规、标准的要求, 提高环境行政决策的科学 性和可行性。推行重大环保决策的公开听证会, 逐步形成 专家论证、公众参与和政府集体讨论决定相结合的行政决 策机制。 
5. 5. 在特殊情况处理方面, 尊重历史、尊重事实、妥善 解决遗留问题, 开拓创新解决经济社会发展新情况 新问题, 实现环保与发展共赢

加强对各地“三重”项目、重大基础设施项目等的服务 保障力度, 坚持发展中保护、保护中发展的原则, 实现环 境保护与发展共赢。深入推进企业清洁生产, 着力培育新 增长点, 推动环保产业发展。通过产业准入、财税、土地 等政策措施，大力发展环保产业，大力拓展工业环保服务 领域。探索建立生态补偿、环境治理专项资金、排污权有 偿交易、第三方治理、污染第三方评估等制度, 开展环境 费改税改革试点, 全面加强环保政策体系构建。以政府职 能转变为契机, 切实做到执法监管和服务企业并重, 创造 良好的发展环境。同时, 在法律、政策、安全、技术、信 息等方面提供服务, 推动执法监管从管制型向服务型转变。

\section{基金项目}

广东省自然科学基金项目“企业环境风险评估与环境 分类管理体系研究”（2014A030310367）、广东省教育厅 普通高校青年创新人才类项目“珠三角地区大气污染的健 康损害与经济评估研究”（2014WQNCX153）

\section{参考文献}

[1] 中国行政管理学会课题组. 深化行政管理体制改革的理论 与实践 $[J]$. 中国行政管理, 2003(3):4-7

[2] 欧文E休斯. 公共管理导论[M]. 北京: 人民大学出版社, 2001

[3] $\mathrm{B}$ 盖伊彼得斯. 政府未来的治理模式[M]. 北京: 人民大学出 版社, 2001

[4] 吴玉宗. 服务型政府: 概念、内涵与特点 [J]. 西南民族大学 学报人文社科版，2004(2):406-410

[5] 北京行政学院公共管理教研部, 北京市领导科学学会. 服务 型政府——公共管理论评[M]. 北京: 中央编译出版社, 2005

[6] 新加坡南洋理工大学南洋公共管理研究生院课题组. 2013 连氏中国服务型政府调查报告[J]. 电子政务, 2014(4):18-33
[7] 胡伟, 柳美玲. 服务型政府、公众满意度与民意调查-基于 中国 32 个城市公共服务民调的研究 [J]. 江苏行政学院学报, 2014(1):103-108

[8] 刘继云, 史忠良. 地方政府推进产业升级转型-以东莞为例 [J]. 经济与管理研究, 2009(3):53-60

[9] 李萍, 谌新民. 人力资本投资、就业稳定性与产业转型升级 [J]. 学术研究, 2012(9):80-86

[10] 何云. 产业群聚与产业的升级改造一以广东东莞的数码 制造业为例 [J]. 南开管理评论, 2002(1):26-28

[11] 2013 年 中国环境 状况公报 [W]. http://jcs.mep.gov.cn/hjzl/zkgb/2013zkgb/

[12] 孟伟庆. 环境管理与规划[M]. 北京: 化学工业出版社, 2011

[13] 张启发, 张会敏, 刘秀玲. 论经济增长与环境保护的共生 [J]. 中国环境管理干部学院学报, 2010(9):38-41

[14] 刘航, 赵景峰, 吴航. 中国环境污染密集型产业脱钩的异质 性及产业转型[J]. 中国人口资源与环境，2012(4):150-155

[15] 王齐. 环境管理促进技术创新及产业升级的问题研究[D]. 济南: 山东大学, 2005

[16] 许士春. 环境管制与企业竞争力一基于 “波特假说”的质疑 [J]. 国际贸易问题，2007(5):78-83

[17] 王俊豪. 政府管制经济学导论[M]. 北京: 商务印书馆, 2003

[18] 张春楠. 论区域环境管制与治理 [J]. 生产力研究, 2001(4):13-14

\section{作者简介}

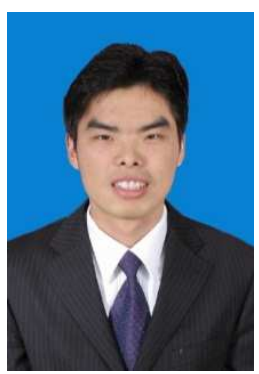

石碧涛（1981-），湖北天门人，东莞 理工学院经济与管理学院讲师, 经济学 博士, 主要研究方向为环境经济、国际 贸易。 